\title{
Comparative Study of Green Logistics Development at Home and Abroad
}

\author{
Jing Hao \\ Zhengzhou Institute of Technology, Zhengzhou, Henan, China, 450044
}

\begin{abstract}
Green logistics based on the maintenance of ecological environment and sustainable development, based on the general logistics to change the one-way relationship. As a new logistics model, green logistics in line with the requirements of sustainable development and human survival and development interests, represents the future direction and trend of logistics development. Chinese implementation of green logistics is urgent and necessary, in the rapid development of green logistics is also facing some problems. The comprehensive understanding of these issues and a deep understanding, are help to find a good solution, so that Chinese logistics industry as soon as possible and international standards.

Keywords: Green Logistics, Development Trend, Comparative Study
\end{abstract}

\section{Introduction}

From the 1920s onwards, logistics in the United States, Japan and some European countries began to rise, to today, the logistics industry has not only become an important economic sector in developed countries, and become an important manifestation of national comprehensive national strength, the national economy The logistics industry in developing countries is also increasingly becoming the leading industry in the tertiary industry, a force in economic development. "However, with the increase in the volume of logistics, logistics activities, as well as the logistics tools and facilities, large-scale, etc. The traditional logistics system on the negative impact of the ecosystem is also growing, specifically: 
"The impact of transport on the environment," the logistics activities can not be separated from the use of means of transport, "the use of vehicles in the course of energy consumption, noise pollution, traffic congestion reduces environmental benefits" In addition, unreasonable distribution of freight outlets and distribution center of the roundabout transport, and further deterioration of the logistics and environmental contradictions"

Custody impact on the environment "In the storage and storage process, the commodity storage center must spray pesticides and other chemicals on the conservation, the surrounding ecological environment pollution" Moreover, some flammable and explosive chemical dangers, If improperly stored, there will be an explosion or leakage of the surrounding environment pollution and destruction of ecological balance "

On one hand, the use of packaging materials, especially the use of a number of disposable industrial and consumer goods packaging is an important part of urban waste, garbage Besieged City and white pollution on the city's sustainable development had a serious negative impact. On the other hand, the so-called luxury packaging, disposable packaging caused a waste of resources, In addition, the waste of packaging materials have not been a good recovery, disposal, The natural environment has also caused a serious impact.

\section{Green Logistics System Analysis}

Functional elements refer to the basic capabilities of the system, these basic functions effectively combined, linked together, has become the overall function of logistics in order to reasonably effectively achieve the objectives of the system. The traditional five basic functions of the logistics system are for the packaging, transportation, handling, storage and distribution processing. Therefore, the functional elements of the green logistics system mainly consist of green packaging, green transportation, green circulation processing and green warehousing.

Transport in the logistics system in a pivotal position, if there is no transport, it can not achieve the delivery of the material. Although transport to the economy to bring a positive effect, but the high energy consumption, high emissions and other features inevitably have a negative impact on the economy.

Green packaging is an important theme of sustainable development, but also Chinese accession to the WTO and the world's packaging industry, international trade convergence of the inevitable choice. The impact of circulation processing on the environment is mainly manifested in: scattered circulation processing process of low energy efficiency, the resulting corners of excess material, emissions of waste, waste and other polluting surrounding environment, there may be secondary pollution. The so-called green circulation processing refers to the circulation of goods in the flow of processing to the environment as small as possible. Including the large-scale, specialized centralized circulation processing, improve the utilization of resources; circulation processing waste centralized processing, and waste logistics smoothly docking, reduce waste pollution and 
waste logistics process pollution. Warehousing in the process of storage, improper operation caused damage to the goods, deterioration, and even leakage of dangerous goods; another unreasonable warehouse layout will lead to an increase in the number of transport or transport circuitous. The so-called green storage, warehouse layout is reasonable, in order to reduce transport mileage, saving transportation costs. Government's role in green logistics is mainly through the development of various environmental regulations and policy instruments to achieve supervision and control. Rodrigue argues that government intervention and legislation are the most direct means of influencing the environment. Haw-Janwu and Stevene Dunn argue that the government plays a regulator, facilitator, and buyer in green logistics. First, the government can legislate and develop administrative rules to save resources, environmental protection requirements of institutionalization, so that the green logistics schedule. Second, the government should be in the form of subsidies, the logistics process in the conservation of resources and reduce pollution behavior to encourage and support the development of environmentally friendly logistics technology. In addition, the Government through the promotion of green logistics education, the main economic entities in the logistics industry and enterprises, logistics enterprises and consumers, and vigorously promote the meaning of green logistics and content, to raise awareness of green consumption, but also help to promote green logistics Implementation and development. Therefore, the government's restrictions, laws and regulations are the external driving force for the implementation of green logistics. However, government regulation also has its limitations. Different enterprises may have different ways of coping with government regulation. Different modes of transportation may also present a completely different management result. In the United States in 1994, logistics managers of the questionnaire, the government's enforcement is the last thing they want to see the way.

\section{Status Quo of Chinese Green Logistics and Its Difference with Foreign Countries}

Although the green logistics has attracted people's attention and is regarded as the inevitable trend of the development of the logistics industry in China, the relevant departments and enterprises have not paid enough attention to the coordinated development of the logistics industry and the environment, Development status as follows:

Green logistics to be successful, not only need to have a green guiding ideology, but also the use of green technology. Chinese green logistics technology is still relatively low, low level of logistics equipment, a variety of modes of transport between the standards are not unified, leading to the convergence can not be effectively achieved between the logistics mechanization and automation level is not high. And lack of the necessary information sharing 
platform, order management, cargo tracking, in the library items and other functions are relatively weak, restricting the efficiency and quality of logistics.

Standardization is the integration of a large number of resources is an important work, the smooth implementation of green logistics depends on the standardization of development. At present, all regions have their own standards, although some national standards, but did not get the popularity, a direct impact on the efficiency of logistics.

Logistics industry needs a huge number of talents, in comparison, Chinese logistics research and education is still quite backward, engaged in logistics research institutions are not many. For enterprises, they do not want to spend energy in research, its investment is very scarce, and some even did not.

The implementation of green logistics is not only an enterprise thing, but also need to rely on government investment, the use of their existing logistics system to strengthen management, and the development of appropriate laws and regulations, standardize the implementation of green logistics. Some developed countries, the Government has developed a lot of relevant policies and regulations to guide the implementation of green logistics. Compared to these developed countries, although our country has been in the development of environmental pollution policies and regulations, but for the logistics industry is very small, which resulted in logistics laws for the lack of environmental protection.

Although Chinese green logistics infrastructure has made great progress, but compared with the developed countries there are still a small gap, such as facilities are not advanced, the lack of uniform standards, the vacancy rate higher. In the technical level, although some companies have introduced GPS, EDI and other advanced technology, but most of the enterprises are still very backward, the implementation of green logistics there is a great difficulty.

Foreign developed countries, logistics education started early, rapid development, has formed a reasonable logistics personnel training system, but also on-the-job personnel also have good retraining measures, these initiatives make the level of logistics talent is high. In China, the rapid development of logistics industry has aroused people's attention to logistics education, investment has increased. However, Chinese logistics education has just started, the level of teachers is mixed, graduate education is just getting started, has been cultivated talents far in short supply. Logistics talent is scarce, green logistics talent is rare, which fundamentally affect the implementation of green logistics process.

\section{The Development of Green Logistics in China}

Modern green logistics industry is an emerging composite industry, involving many departments. In order to avoid multiple government departments and ensure coherence among government departments, we should establish the necessary coordination mechanism for government departments to establish the department in charge of logistics management. Its main functions should be the development of modern logistics policy, coordination of national and regional 
logistics development planning, research and development to solve major problems, the organization to promote the development of modern logistics industry. The development of green logistics is inseparable from the strong policy guarantee, therefore, must establish a set of perfect laws and regulations and policy system to effectively regulate, supervise and encourage the behavior of logistics enterprises. Through the environmental legislation, the sewage charge system, the permit system and the establishment of green logistics standards to restrain and intervene in the logistics of external diseconomy; through the development of green subsidies, tax support policies, preferential policies to encourage and guide the logistics of the main behavior and promote the healthy development of green logistics.

The perfect logistics information system is an important foundation for the development of green logistics, and it is helpful to improve the utilization and economy of logistics resources. The government should lead enterprises to use advanced information technology, including Total Quality Management (TQM), Electronic Data Interchange (EDI), Radio Frequency Technology (RF), Global Positioning System (GPS) and Enterprise Resource Planning (ERP) Information management level, and logistics standardization is an important basis for resource integration work. In order to solve the problems of logistics standardization and the development direction of international logistics standardization, the government should pay more attention to the standardization of logistics. It should be done in terms of logistics terminology, measurement standards, technical standards, data transmission standards, logistics operation modes and management standards. Good foundation work.

Green logistics is a new thing, the Government should vigorously support and guide the green logistics research, strengthen enterprises, institutions of higher learning, scientific research institutions cooperation between the formation of a virtuous cycle of combining production and research to strengthen the application of logistics technology development and application. In the logistics personnel training, multi-level, diversified logistics education system is to ensure that the logistics industry to form a reasonable talent structure, improve the logistics management level of the decisive factor. The government should encourage colleges and universities to offer courses in modern logistics, carry out multilevel academic education such as undergraduate, master's and doctoral degrees, accelerate the certification of vocational qualification training, optimize the logistics education teachers, improve the quality of logistics education, and continuously enrich the logistics teachers.

\section{Conclusion}

As the Chinese economy has become a part of the global economy, we must accelerate the green construction of logistics, logistics enterprises must speed up the adjustment and integration, or will lose competitiveness. Therefore, we should strengthen the establishment and perfection of the logistics greening policy and theory system, improve and adjust the logistics system target, logistics 
facilities and logistics activities organization, realize the overall optimization of the logistics system and the minimum damage to the environment, Will be conducive to Chinese logistics management level.

\section{References}

[1] Liu Hongmei. Development of Changzhutan Green Logistics Circle in the Background of Central Chinese Rise [J]. China Logistics \& Purchasing, 9(2), pp. 13-35, 2012

[2] He Lan Tao. Analysis of Chinese green logistics development [J] China Business, 25(1), pp. 14-25, 2013

[3] Wang Wei, Wu Yong. The system engineering theory and method in the enterprise strategy analysis of the application $[\mathrm{J}]$. Small and medium enterprises management and technology, 12(8), pp. 13-22, 2011

[4] Zhao Yang. The rise of Central China to Wuhan modern logistics industry opportunities [J]. Contemporary Economy, 7(12), pp. 25-45, 2010

[5] Wu Feng. Based on green supply chain management of agricultural products logistics [J] .Economic Economics, 12(1), pp. 16-33, 2009

[6] Wang Zhenqiong, Zhang Dandan. Logistics development and the rise of central China [J] .Financial Economics, 22(1), pp. 18-22, 2009 